\title{
Challenges of Entrepreneurial Education in Nigerian Universities: Towards a Repositioning for Impact
}

\author{
Adenike Adetola Agbonlahor \\ Federal College of Education, Abeokuta, Nigeria
}

Doi:10.5901/jesr.2016.v6n1p208

\begin{abstract}
Entrepreneurial education course were introduced into the undergraduate curriculum of University students in Nigeria in 2006. The focus was to equip graduates with requisite skills for entrepreneurial success after school. The overarching objective of the program was to reduce youths unemployment; especially among school leavers, in Nigeria. Over the years, while graduates unemployment has not abated, there is a growing national discontentment on the socio-economic relevance of the course in Nigeria education. This inability to meet its introduction objectives has led to many uncoordinated revisions and changes in the pedagogical structure of the curricula over the years. To reposition entrepreneurial education for impact, there is a need to critically and comprehensively review implementation challenges as reported over time. The study adopted a review methodology approach of extant literatures and publications in the last decade. The theoretical underpinning of the methodology is based on structural functionalism in order to achieve a holistic system diagnosis. The internal challenges that bother on funding, relevance and harmonization of curricula were found to be more invasive than the external policy-related challenges. It is recommended that the internal and external factors need a redress to refocus and reposition Entrepreneurial Education for impact in the country.
\end{abstract}

Keywords: Entrepreneurial education, implementation challenges, repositioning

\section{Introduction}

Citizen's economic empowerment is a major goal of most developing countries such as Nigeria. The high population growth rate in Nigeria in the last decades (estimated at 4.3\% annually) has been associated with a youth bulge and high level of unemployment; especially among school leavers. These have resulted to associated social problems such as high rural-urban migration, underemployment and illegal immigration across national and continental boundaries. To reverse this trend, especially as it affects graduates' unemployment, the government of Nigeria in 2006 introduced entrepreneurial education $(E E d)$ as a compulsory curriculum in University with the aim of preparing graduates for entrepreneurial success through private sector initiative. This was based on the hard reality that universities should change their orientation as mills for job seekers rather than job creators. This initiative was to serve as the flagship to drive economic and social reconstruction against the backdrop of youth unemployment and the thousands of school leavers every year. Ojiefo (2012) reported that rising graduate unemployment and the low entrepreneurial drive amongst school leavers in Nigeria, led to the need to reposition higher institutions as centers for building self-sustaining graduates that will be future captains of industries. EEd was introduced in tertiary institutions to produce graduates with special professional and entrepreneurial skills needed to champion economic growth through investments.

While studies abound on the importance as well as the private and social benefits of EEd to the economy, there is a dearth of information on the comprehensive implementation challenges review of the EEd in Nigeria; to map its effect and challenges in such a way as to reposition it for impact. This is particularly research worthy because a review of the implementation challenges will bring to the fore, any systemic limitations in the implementation. The broad objective of the study is to review the challenges of EEd in Nigerian Universities as a means of repositioning it for impact. Specifically, the study aims to map key issues in EEd that limits its implementation in Nigerian Universities. The report is structure in the following order: the introductory section reviews the role of education and the place of EEd in national development. The theoretical framework sets forth the theoretical underpinning of the study, the discussion and conclusion section highlights the challenges and the pathway for repositioning EEd for impact. 


\subsection{Education and National development}

The role of education as the engine of social and economic change and transformation cannot be overemphasized in any society. Education as a lifelong process seeks to re-socialize individuals to adopt behaviors and lifestyles that are consistent with and supports the development goals of the society. Unachukwu (2009) asserts that, through education the individual citizen is fully equipped to contribute meaningfully to the social and economic development of his nation. Bloom, Canning and Chan (2005) indicated that in a knowledge economy, education provides the means to help individuals develop self-worth. Education also equips people with skills and attitude to participate in social, political and economic development of the economy. The Nigeria national policy on education, adequately, posit that education is the most important instrument for propelling change, as no fundamental change can occur in any society except through educational revolution that impact on the intellects. In realization of the all-important role of education, government at all levels, have used education as a means of inter-phasing with people-led change.

\subsection{The objective and focus of Entrepreneurial education}

The objective of EEd was to continuously foster entrepreneurship culture amongst students and faculty with a view of not only educating them but to also support graduates of the system towards establishing and also maintaining sustainable business ventures (Bloom, Canning and Chan 2005). EEd as a form of education is a process of adjustment. It involves the development of the social and economic efficiency of individuals by progressively upgrading their thought pattern and eventually, their way of life. Mauchi et al., (2011) reported that the objective of EEd is to provide individuals with the ability to recognize commercial opportunities and the knowledge, skills and attitudes to act on them. Oduwaiye (2009) reported that EEd focuses on assisting trainee students on how to develop positive attitudes, innovation and skills for self-reliance rather than depending on the government for employment.

EEd seeks to empower students with new skills to be able to harness opportunities, be self-reliant and become job-creators and not job-seekers on graduation. The training on EEd should therefore, be focused on developing capacities to collect, analyze, organize and critically evaluate information for business decision making. It was envisaged at conception, that entrepreneurship education will not only equip graduates with the skills and motivation for successful entrepreneurship, it was also to provide the needed prop to boost private sector investment to curb the problem of unemployment among school leavers. Dirk (2009) reported that though education is the clearest path to individual opportunity and societal growth but, that, EEd is especially vital to supporting a more robust global economy. EEd inculcates new ideas to life through investments, creativity and value adding innovations (Okah and Odelola, 2009; Nwosu and Ohia 2009). At introduction in most European universities, EEd was focused to develop entrepreneurial capacities and mindsets of students (Wilson 2008). This purpose driven nature of EEd influences the curricula provisions of institutions in Europe. Lee and Wong (2005) assert that EEd is a catalyst for economic development and job creation in any society and therefore the teaching should be focused on elaborating this role. Also, Akinkugbe (2004) surmise that EEd introduction objective is to develop in graduates, the skills, entrepreneurial orientation and mindset to prepare for the business, vocational and professional lives after their formal university education. Osuala (2010) summarize the objectives of EEd in Nigeria to include : 1) provision of meaningful education for youth which could make them selfreliance and subsequently encourage them to self-dependent 2) providing graduates with the training and support necessary to help them establish a career in small and medium size business 3 ) providing graduates with training skills that will make them meet the manpower needs of the society 4) providing graduates with enough training in risk management to make risk bearing possible and easy 5) stimulate industrial and economic growth of rural and less developed area 6) providing graduates enough training that will make them creative and innovative in identifying new business opportunities and 7) providing small and medium sized companies with the opportunity to recruit qualified graduates who have receive training and tutoring in the skills relevant for business management.

The focus of the EEd is to produce entrepreneurs. The entrepreneur is someone who ventures, by taking risks, into a business involving planning, organizing and coordinating use of materials and money to make a profit by producing goods or rendering services (Singh and Sharma 2011). The entrepreneur is a risk taker and it is envisage that the risk taking behavior is informed through training and understanding of the business terrain. An entrepreneur is someone that is never satisfied with the status quo, someone who is willing and able to convert new ideas or invention into a successful innovation. By and large, the entrepreneur is the person who perceives a business opportunity through risks analyses and takes advantage of the situation to make a profit. Entrepreneurship on the other hand, is the service rendered by the entrepreneur (Akanwa \& Agu, 2005; Lee and Wong 2005; Ogundele, Sofoluwe \& Kayode, 2012). At inception, it was 
estimated that by 2014 over 340,000 graduates would have received the requisite training provided by the course to be entrepreneurs. It is expected that these graduates will form the bulk of private investments initiators as jobs creators. However, almost a decade since its introduction, the upward trend in graduate/youths' unemployment has not abated, but rather, it has taken unprecedented dimensions.

\subsection{Entrepreneurial Education in Nigeria}

Entrepreneurship education was introduced in the United States in the 1940s. Over the years, the concept and content has been expended, adopted and integrated into the education curricula of other countries. McMullan and Long (1987) reported that EED is an integral part of the economic strategy for fostering job creation and reducing unemployment in any nation. EED has become such an important component of formal education that in 1998, UNESCO World Conference recognized its value and advocated cultivating entrepreneurship and skills in higher education as a development strategy for many emerging economies (UNESCO 2008). The UNESCO report highlighted that through EEd students are able to gain experiences that give them the ability and vision of how to access and transform opportunities of different kinds. This presupposes that EEd goes beyond formal classroom teaching to incorporate training to increase students' ability to anticipate and respond to societal changes for business creation. Tulgan (1999) outlined the functional basis of EEd as education and training which allows students to develop and use their creativity in entrepreneurial development of the country.

In 2006, the government of Nigeria announced the introduction of EEd as entrepreneurship studies, to be integrated in the University curriculum as a compulsory course for students irrespective of area of specialization Okojie (2009). Effectively, the implementation started in the 2007/2008 academic session. In pursuance of the full implementation of EEd, most of universities established a coordinating center for entrepreneurship education to support students' training. The Nigerian University Commission (NUC) was given presidential directives by the Ministry of Education to supervise and coordinate the programmme of introducing EEd in Nigerian institutions of high learning (Okojie 2009). At inception, EEd was harped as the panacea for youth unemployment and a catalyst for sustained private sector-led growth. EEd was introduced to provide students in tertiary institutions with the knowledge, skills and motivation to encourage entrepreneurial success in a variety of ventures (Aliu 2008). To make the delivery effective, the NUC prescribed the following ten areas in the Benchmark Minimum Academic Standard (BEMAS) guide for teaching EEd in Nigerian Universities: 1)Introduction to entrepreneurship 2)entrepreneurship in theory and practice 3) Types of business, staffing and marketing 4) capital requirement and raising capital 5) financial planning and management 6)feasibility studies and reports 7) Innovations 8) legal issues in business 9)insurance and environmental consideration, and 10) possible business opportunities in Nigeria. However, about ten years down the road, the excitement and momentum generated at the introduction of EEd have waned as a failed expectation.

\section{Theoretical framework}

The study adopted a review methodology of extant scholarly literatures published in the last ten years on entrepreneurial education in Nigeria. The review method adopted covered available research and scholarly literatures and government publication in the area of EEd in Nigeria since its inception in 2006. The structural functionalism approach of the review presents the basis for identify weak components in the implementation framework for an efficient functioning. To ensure that the repositioning will furnish the needed condition for actualizing the set up objectives the reviewed leverage on the identified structural and implementation bottlenecks. The theoretical underpinning of the methodology is based on structural functionalism. Structural functionalism theory is based on assessing (individually and collectively) the support/components or framework on which a system depends. Structural functionalism ensures that the process of identifying lacunas in a system bears directly on the impact in the functioning of the system. A basic assumption of the theory is that the unit of analysis is a system with clear structural delineation for the various components that are interrelated and inter-dependent. The goal seeking component of EEd means that the curriculum should be as functional as far as possible. Functional curriculum is one that is designed to teach students skills, through formal interaction to equip them to function as competent and accepted adults in the society. Functionally, EEd is a training that stimulates in the students the urge to better their lives; by generating value through the creation or expansion of economic activities and the identification and exploitation of new products, processes or markets. This functional analysis of the system hinges on the submission of Consortium for Entrepreneurship Education (2012) that EEd should be differentiated from a textbook focused course. 


\section{Implementation and Impact Challenges of EEd in Nigeria}

The entrepreneur is a risk taker. The propensity to take risks is reinforced through training and understanding of the business terrain. To inculcate the requisite training and confidence to be successful entrepreneurs, there is the need to optimize both the internal and external conditions that stand as limitations. EEd as a practical oriented venture, with lifelong impact on individuals and the society as a whole, needs to be adequately focused; taking into consideration the needed support structure for impact. As highlighted above, repositioning EED for impact should start from a comprehensive review of the implementation challenges by comparing with global best practices. The study, extensively reviewed existing literatures and publications (local and international) that harp on the ingredients for successful national EEd. In repositioning EEd for impact in Nigeria, attempts should be made to analyze the challenges that presently confront the system as an educational venture with respect to the content and delivery components. The functional challenges identified from the reviews are summarized below.

\subsection{Capacity of lecturers/instructors}

The capacity of lecturers and instructors that anchors EEd in most universities have been fingered as a reason for the poor quality delivery. There is a dearth of lecturers and instructors with practical training in EEd or entrepreneurship. When we consider that most instructors have not been entrepreneurs it seems obvious that this is a major area of need. It was for this reason that, at introduction, instructors with training in business studies only were used for the delivery (Uche et al. 2009; Enu, 2012). This was due to the large misconception that equated EEd to business studies; despite the difference in scope and focus of the two courses. In USA, institutions employ full-time staff who are exclusively committed to entrepreneurship education program, teaching entrepreneurship (Zhuo and Haixia, 2012). In contrast, in Nigeria, the majority of entrepreneurship instructors are from traditional disciplines such as economics or business administration. Apart from the deficient qualifications of instructors, the lack of entrepreneurial consciousness is also indicted as a challenge to the quality delivery for impact of EEd in Nigerian Universities (Amoor 2008).

\subsection{Absence of curricular capacity to support the training}

The obvious lack/absence of a curricular guide to inform a pedagogical delivery in the methodology of EEd is identified by many researchers as a major drawback in the system. A good curriculum must be phased and integrated to ensure that there is a systematic upgrading of knowledge over time. The concept of "problem-based learning activities" is not used in developing the curriculum, and this was observed to be common problem of most EEd curricular (The Consortium for Entrepreneurship Education, 2012), the dependence on a written business plan as preparation for starting a business is a limiting educational approach. It has also been reported that the existing University curriculum structure has a startup challenge for EEd (Anyaogu 2009). There are no pre-requisites introductory course, at the lower level (EEd was introduced as a third or fourth year level course) upon which the newly introduced course was predicated. The present situation where EEd tends to be offered in stand-alone courses rather than being integrated into the content of courses in other departments or disciplines does not create the avenue for harmony and sustained interest by the students. The NUC benchmark for EEd is 6 credits hour, but due to the bloated existing credit loading most of the Universities cannot accommodate the 6hours and as such EEd is taught as a onetime 2 credits hour with a very shallow content Fashanu and Okunloye (2010) extended the curricular limitations and submitted that, because the existing University curriculum is already overstretched with accredited courses to maximum credit hours; most universities adopted a zero credit hour loading for the newly introduced EEd. This development depreciated the essence and status of EEd as well as the interest of the students on the courses. The implication of this is that there is a need to harmonize and align the curriculum of EEd to build on a practical and systematic introduction of themes.

\subsection{Lack of infrastructural support}

The infrastructure needed to deliver quality and practical oriented EEd requires huge investment in capital. Inadequate funding is indicted in the poor infrastructural support needed to drive quality delivery of EEd. Both hard and soft infrastructure is needed as prop for the system. This limitation subsequently frustrates the integration of entrepreneurship in academic programs in Nigerian universities. The lack of support infrastructure and infrastructural failures results to high transaction costs which makes delivery very expensive and inefficient. 


\section{Favourable policy environment and lack of government support}

The lack of adequate policy framework to serve as lunch-pad for the entrepreneurial skills acquired in school to blossom has been harped as a reason for the lack of entrepreneurial drive among school leavers. Lack of access to credit/ loan, absence of tax rebates, mass poverty, high level of inflation, technological infraction, political instability and insecurity of lives and properties are some of the manifestations of the absence of this needed support (Adiele 2010; Maina 2014). In USA, EEd has been most successful because most Universities are uniquely able to include and integrate entrepreneurship because of federal funding as provided in the Perkins Act (As reported by The Consortium for Entrepreneurship Education 2012). Inconsistencies in government policies in Nigeria, especially as it affect business investments incentives and provision of enabling policy environment for the development of small and medium enterprises are indicated as reasons for the poor take off of EEd. Entrepreneurship Skills have been reported as extremely important to the future, and since EEd teaches skills for life - problem solving and creative thinking, it is important that the experiences should begin earlier in grade schools rather than in the University. In China, for example, the government supports young entrepreneurs through direct financial support, business incubators support at startup and annual business plan competition organized yearly by the ministry of science and technology. Unfavorable societal attitude to technical and vocational education is also tied to the lack of support for EEd. Direct and indirect supports are needed to encourage and stabilize young entrepreneur in the highly risky business environment.

\subsection{Overemphasize on theory delivery}

The present method of teaching and EEd has been described as a mechanistic delivery. The method leaves no room for the students to engage individually with the hard realities of the business environment. The high students/lecturer ratio in Universities occasioned by expanded admission quotas; usually beyond the carrying capacities of the facilities available has been suggested as the reason for de-emphasizing the practical components. The absence of co-curricular activities such as entrepreneurship clubs, lectures and speakers, workshops and seminars, business plan competitions, internships, and venture incubators are key drawbacks of EEd in Nigeria. In USA institutions offering EEd, occasionally business executives are invited to teach a full course, make a presentation, or share their experiences with students. Akpomi (2009); Nwosu and Ohia (2009); Brown (2012) and Offorma, Egbe and Eze (2012) suggested that inadequate facilities and equipment for teaching and learning in practical-related courses was the reason why EEd has not been able to record a significant impact in Nigeria industrialization drive and reduction of youth unemployment.

\subsection{Absence of research support and linkages}

At conception, it was envisaged that EEd will leverage on products of students researches in the Universities. As obtainable in China and the other Asian countries, the EEd is based on harnessing the commercial aspect of research and development. This is a missing component in Nigeria education. There is a pronounced absence of research support and most of the research endeavors of the students are not targeted and are not applied to real life adoption. Absence of adequate funding, research capacities and linkage opportunities are obvious reasons for this limitation. Developed countries, such as USA and China, that have utilized EEd as a key driver for economic growth, creativity and welfare enhancers have done so with sustainable research support and linkages with private sector firms with commercial goals. Zhuo and Haixia (2012) reported that in China, most universities maintain an entrepreneurship fund to evaluate students' business plan and finance those that show special promise. This support (external or internal) is conspicuously missing in Nigeria.

\section{Conclusion and Recommendations}

Job creation, economic prosperity and improvement of social welfare are critical national goals and entrepreneurship development is a catalyst on the path to their accomplishment. EEd as with all educational venture seeks the transformation of character and attitude of individual through a systematic presentation of ideas needed to cause a reorientation in behaviors. EEd was introduced as a compulsory component of University education in Nigeria in 2006. The importance and focus of EEd in developing entrepreneurial skills and its long term benefits of reducing youth unemployment and promoting sustained economic growth were harped at its introduction, and widely accepted as the panacea for economic recovery. There is no gainsaying the need for EEd in Nigeria, especially at an auspicious time like 
this; with declining government revenue, increasing youth's unemployment, decreasing public investments and vanishing private sector businesses. However, about ten years down the road, the excitement and momentum generated at the introduction of EEd have waned as failed expectations. The study has reviewed the implementation of EEd in Nigeria with the view at identifying systemic limitations that has hampered the actualization of its benefits. Identification and a review of the implementation challenges present the needed initial approach to repositioning EEd as a viable tool for economic reconstruction in Nigeria. The functional approach adopted in the analysis helps for a holistic system focus to ensure that all necessary inter-dependent components are assessed in relation to goal.

The study concludes that, EEd as a practical oriented venture, with life-long impact on individuals and the society as a whole needs to be adequately focused; taking into consideration the needed support structure for impact. There is the need to reposition EEd to effectively play the all-important roles that other emerging economies have benefited from it. To fast track the attainment of EEd laudable objective in Nigeria, the universities must offer more practical coursework, blending the theory in the traditional economic literature with the tangible needs of everyday business. EED must not be text book focused rather, it should be experiential, hands-on and be action driven to give students a real-world experience.

Based on the findings of the study, the following recommendations are proffered as milestones in repositioning EEd for impact:

1. Urgent need for Universities to review and align EEd curricula by linking to real-world business challenges. Entrepreneurship is best learned on the ground; by connecting mistakes, successes, and strategies with real world business challenges makes entrepreneurship as real as possible for students

2. Universities should identify and partner with businesses to strengthen the practical component of the training. Apart from the internship component business executives should be invited to deliver lectures on key areas of business challenges in the Nigerian context. By so doing the universities will be able to incorporate the experiences of professionals and guest lectures from the business world - This "value-added element" is invaluable and teaches more than classroom texts

3. Government direct assistant to facilitates and enable students and graduates startup viable business venture. This is in acknowledgement of the risky business climate in Nigeria. Young entrepreneurs need to be facilitated and protected.

\section{References}

Adiele, E. E (2010). Entrepreneurship Education a strategy for achieving self-reliance and Economic development. Journal of Management and Enterprise Development.7: (3)

Akanwa, B., \& Agu, C. N. (2005). Entrepreneurship: Theory and practice in Nigeria. Owerri, Nigeria: Resources Development Centre.

Akpomi, M. E. (2009). Achieving millennium development goals (MDGs) through teaching entrepreneurship education in Nigeria higher education institutions (HEIs). European Journal of Social Science, 8(1), 154-157.

Amoor, S. S. (2008). Integrating entrepreneurship education into business education curriculum in Nigerian universities. Zaria Journal of Liberal Arts, 2(2).

Anyaogu, R.O. (2009). Managing entrepreneurship education at tertiary level: A panacea to unemployment. African Journal of Educational Research and Development, 3(2): 99-107.

Bloom, D. Canning, D. \& Chan, K. (2005), Higher Education and Economic Development in Africa. A research paper commissioned by the World Bank (AFTHD) submitted on the 20th September, 2005

Brown, P. B. (2012). Why everyone will have to become an Entrepreneur (Cloud Sourced Version) Retrieved from http://www.forbes.com/sites/actiontrumps everything/2015/08/03/why

Enu, D. B. (2012). Enhancing the entrepreneurship education in Nigeria. American Journal of Social Issues and Humanities, 2(4), 232239.

Fashanu, S.O \& Okunloye, R.W (2010). Higher education and Entrepreneurship education challenges for Nigerian Universities and graduate employment. A publication of Centers of Entreprenuiral studies, Ajayi Crowther University, Oyo. Pp 13

Guerrero, M., \& Urbano, D. (2012). The development of an entrepreneurial university. The Journal of Technology Transfer, 37(1), 4374.

Higher Education in the Twenty-First Century Vision and Action; UNESCO: Paris, France, 1998. Available online: http://unesdoc.unesco.org/images/0011/001166/116618m.pdf (Accessed on 20 August 2015).

Lee, L. \& Wong, P (2005), Entrepreneurship Education A compendium of Related Issues. NUS Entrepreneurship Centre Working paper, July, 2005.Wong (2008)

Maina, S. (2014). The role of entrepreneurship education on job creation among youths in Nigeria International Letters of Social and Humanistic Sciences Vol. 15 (2014) pp 87-96

Mauchi, F. N; Karambakuwa, R. T. Gopo, R. N: Kosmas, N: Mangwende, S \& Gombarume, F. B. (2011). Entrepreneurship education 
lessons: a case of Zimbabwean tertiary education institutions. International Research Journals, Vol. 2(7):1306-1311.

McMullan, W.E. \& Long, W.A. (1987) .Entrepreneurship education in the nineties. J. Bus. Venturing,2, 261-275.

Nwekeaku, C (2013) Entrepreneurship Education and Challenges to Nigerian Universities Journal of Education and Practice, Vol.4, No.3,

Nwosu, B. \& Ohia, A. (2009). Managing entrepreneurship education at the university level in Nigeria: A panacea for graduate selfemployment. African Journal of Educational Research and Development, 3(2): 49-53.

Oduwaiye, R. O. (2009). Entrepreneurship education in Nigerian universities: Implementation and way forward. Advances in Management, 8(1), 60-67.

Offorma, G.C., Egbe, C. I. \& Eze, K.O. (2012). Analysis of Entrepreneurial Skills Acquisition Content of Language Education Curricula at the University of Nigeria. Nigerian Journal of Curriculum Studies, 19 (3), 94-101.

Ogundele, M. O., Sofoluwe, A. O. \& Kayode, D. J. (2012).Integrating entrepreneurship skills acquisition in to the National Youths Service Corps (NYSC) Programme in Nigeria. Journal of Entrepreneurship and Management. 1(3), 24-28.

Ojeifo S. A. (2013). Entrepreneurship Education In Nigeria: A Panacea For Youth Unemployment, Journal of Education and Practice Vol. 4, No. 6, 2013,

Okah, R. \& Odelola, J.A. (2009). Entrepreneurship education at tertiary level in rivers state: A situational analysis. African Journal of Educational Research and Development, 3(2): 108- 121.

Okala, O. F. (2008). Unemployment experience in Nigeria: The impact of vocational skills training. Journal of Pedagogy of Education and Development, 10(1-2), 18-25.

Okojie, J.A. (2009). Imperative of the Federal Government Directive On The Establishment of Entrepreneurship Studies in Nigerian Universities. A Paper Presented at the 1st Conference on Effective Implementation of Federal Government Seven-Point Agenda Held at NUC, Abuja, Feb.4-6

Osuala E. C. (2010). Principles and methods of business and computer education. Enugu: Cheston Agency Ltd Pub, Nigeria

Singh, P.K. \& Sharma, P. (2011). Rural women empowerment through entrepreneurship development. International Journal of Asian Social Science, 1(2): 24-26.

The Consortium for Entrepreneurship Education (2012). The State of Entrepreneurship Education 2012, Columbus, OH USA

Tulgan, B. (1999). Generation x: The future is now. Entrepreneur of the year magazine. Fall. 42.

Uche, C.M. and Adesope,O.M. (2009). Capacity building for entrepreneurship education: State of the art in university of Port Harcourt, Nigeria. African Journal of Educational Research and Development, 3(2): 86-98.

Unachukwu, G. O (2009). Issues and Challenges in the Development of Entrepreneurship Education in Nigeria. An International MultiDisciplinary Journal, Ethiopia 3(5)213-226.

UNESCO (2008). Promoting Entrepreneurship Education in Secondary Schools. Final report of UNESCO inter-regional Seminar on promoting entrepreneurship education in Secondary Schools, held in Bangkok, Thailand on 11th - 15th February, 2008

Wilson, K. (2008). Chapter 5: Entrepreneurship education in Europe. In Entrepreneurship and Higher Education; Potter, J.E, Ed.; OECD Publishing: Paris, France, pp. 98-115.

Zhou, M \& Haixia Xu (2012). A Review of Entrepreneurship Education for College Students in China. Adm. Sci. 2012, 2, 82-98 